\title{
A neuroscientific account of how vestibular disorders impair bodily self-consciousness
}

\section{Christophe Lopez*}

Laboratoire de Neurosciences Intégratives et Adaptatives - UMR 7260, Centre Saint Charles, Fédération de Recherche 3C, Centre National de la Recherche Scientifique - Aix-Marseille Université, Marseille, France

\section{Edited by:}

Pierre Denise, Université de Caen Basse-Normandie, France

\section{Reviewed by:}

John S. Butler, Albert Einstein College of Medicine, USA

Isabella Pasqualini, Ecole

Polytechnique Fédérale de Lausanne, Switzerland

\section{${ }^{*}$ Correspondence:}

Christophe Lopez, Laboratoire de Neurosciences Intégratives et

Adaptatives - UMR 7260, Centre Saint Charles, Fédération de Recherche $3 C$ - Case B, Centre National de la Recherche Scientifique - Aix-Marseille Université, 3 Place Victor Hugo, 13331 Marseille Cedex 03, France

e-mail: christophe.lopez@univ-amu.fr
The consequences of vestibular disorders on balance, oculomotor control, and self-motion perception have been extensively described in humans and animals. More recently, vestibular disorders have been related to cognitive deficits in spatial navigation and memory tasks. Less frequently, abnormal bodily perceptions have been described in patients with vestibular disorders. Altered forms of bodily self-consciousness include distorted body image and body schema, disembodied self-location (out-of-body experience), altered sense of agency, as well as more complex experiences of dissociation and detachment from the self (depersonalization). In this article, I suggest that vestibular disorders create sensory conflict or mismatch in multisensory brain regions, producing perceptual incoherence and abnormal body and self perceptions. This hypothesis is based on recent functional mapping of the human vestibular cortex, showing vestibular projections to the primary and secondary somatosensory cortex and in several multisensory areas found to be crucial for bodily self-consciousness.

Keywords: vestibular system, body schema, body image, touch, caloric vestibular stimulation, bodily consciousness, multisensory integration

\section{INTRODUCTION}

The consequences of vestibular disorders are dramatic as they incorporate a wide range of symptoms including vertigo, loss of balance, and blurred vision. It is accepted that vertigo results from the activation of the vestibulo-thalamo-cortical pathways, postural instability and falls from abnormal vestibulo-spinal reflexes, and blurred vision from impaired vestibulo-ocular reflexes (Curthoys and Halmagyi, 1995; Borel et al., 2008). More recently, deficits in spatial navigation and memory tasks have been related to vestibular disorders, presumably due to vestibular projections to the cortex and hippocampus (Smith, 1997; Brandt et al., 2005).

In addition to these deficits, vestibular patients sometimes report abnormal bodily perceptions. The role of vestibular organs in bodily perceptions has captured the attention of pioneering researches on body representations such as those of Bonnier (1893, 1905), Schilder (1935); Lhermitte (1939), and Menninger-Lerchenthal (1946). These authors reported cases of patients losing connections with their body, experiencing deformations of their body, or disembodiment. Yet, the mechanisms underpinning these disorders remain poorly understood. One reason is that bodily disorders have to date not been quantified experimentally in vestibular patients despite the development of psychophysical methods to measure various bodily experiences (Blanke, 2012). Secondly, the comprehension of how vestibular dysfunction modifies bodily consciousness has been hampered by scarce descriptions of the vestibular cortex. In the present article, I argue that recent progresses in functional mapping of the human vestibular cortex and advances in the neuroscience of bodily self-consciousness afford a neuroscientific explanation of the mechanisms at the basis of bodily disorders in vestibular patients.

\section{A NEUROSCIENTIFIC FRAMEWORK BASED ON THE MULTISENSORY NATURE OF THE VESTIBULO-THALAMO-CORTICAL PATHWAYS}

The neuroscientific framework to understand bodily disorders in vestibular patients is based on the multisensory nature of the vestibulo-thalamo-cortical pathways, a finding that was unknown from Bonnier and Schilder when they described the consequences of vertigo on body perception. A vestibulo-visuo-somatosensory convergence has been found in all vestibular relays, including vestibular nuclei, thalamus, and cerebral cortex (see Figure 1 and Table 1 for details).

Normal sensorimotor development calibrates synergies between actions and their sensory consequences at both behavioral and neural levels (Held and Hein, 1963). For example, head rotations to the right are normally encoded with leftward optic flow and matching proprioceptive signals from the neck. Corresponding synergistic responses exist in all vestibulo-thalamo-cortical structures and recent studies showed that vestibular and visual responses combine "in a statistically optimal fashion," in accordance with the predictions of Bayesian models (MacNeilage et al., 2007; Fetsch et al., 2012). Importantly, sensory conflicts may disorganize calibrated synergies at the neural level (e.g., visuo-vestibular mismatch alters neural responses in vestibular nuclei; Waespe and Henn, 1978). Here, I propose similar mismatch is produced by various peripheral vestibular disorders (e.g., Menière's disease, vestibular neuritis). I suggest that vestibular disorders provide the brain with erroneous vestibular signals about current selfmotion and position, and create sensory conflicts (or mismatch) leading to a perceptual incoherence. That is, abnormal vestibular signals would induce misinterpretation of tactile, proprioceptive 


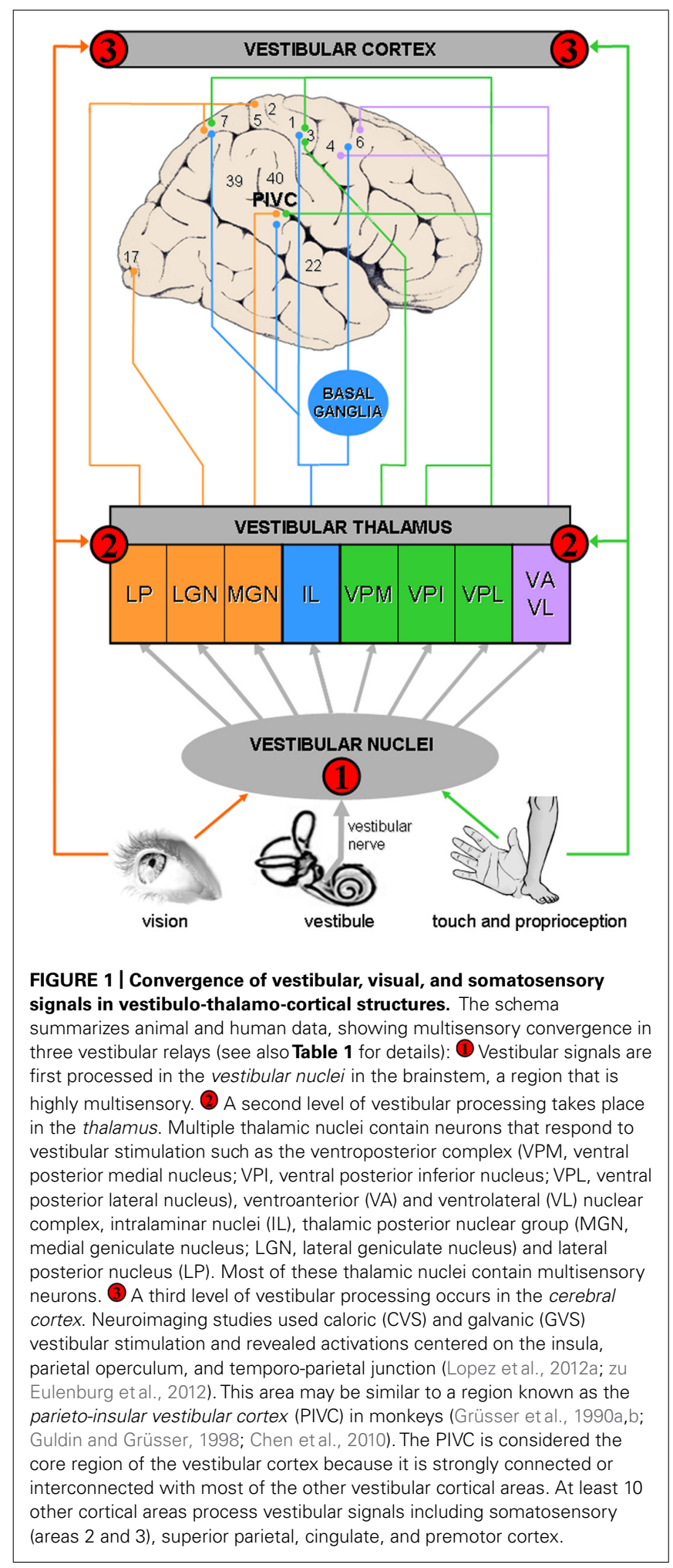

and visual signals from the body and, as a consequence, distort bodily self-experience. In support of this view are recent data on self-motion perception showing that even in the case of large visual-vestibular conflicts, vestibular information is not disregarded and both signals are "mandatorily fused" (Prsa et al., 2012).
Other studies suggest that during multisensory conflicts, vestibular cues are weighted higher (Butler et al., 2010; Fetsch et al., 2012). These data indicate that participants strongly rely on vestibular signals, even when this information contradicts other sensory cues.

In the following sections, I describe a detailed neuroscientific account of how vestibular dysfunction can distort various aspects of the bodily self.

\section{DISTORTED BODY SCHEMA AND BODY IMAGE CLINICAL DESCRIPTION}

Vestibular disorders may impair two fundamental aspects of mental body representations known as body schema and body image. They refer to different types of representations of body configuration and metric properties, including the size and shape of body parts, and body position in space (e.g., Gallagher, 2005; Berlucchi and Aglioti, 2010; de Vignemont, 2010; Longo et al., 2010; Serino and Haggard, 2010). Although body schema and body image have been proposed to be of mostly proprioceptive and visual origin, a vestibular contribution was postulated over a century ago. Bonnier $(1893,1905)$ described striking examples of distorted perceptions of the body shape and size in vestibular patients. For example, one of his patients "felt his head became enormous, immense, losing itself in the air; his body disappeared and his whole being was reduced to only his face." Interestingly, Bonnier coined the term "aschématie" (indicating a "loss" of the schema) to describe distorted representations of the volume, shape, and position of the body and body segments (Vallar and Papagno, 2003; Vallar and Rode, 2009). Several decades later, Schilder (1935) described distorted body schema and image in vestibular patients who reported that the "neck swells during dizziness," "extremities had become larger," or "feet seem to elongate" (p. 117). Altogether, these sensations are comparable to neurological symptoms of asomatognosia (e.g., Dieguez et al., 2007), even if evoked solely by peripheral vestibular disorders.

\section{EXPERIMENTAL EVIDENCE}

Several lines of evidence from neurology and experimental psychology support the idea that abnormal body image and schema might change due to misinterpretation of bodily signals created by vestibular disorders. All of them are based on studies showing the influence of caloric (CVS) and galvanic (GVS) vestibular stimulation on the perceived shape and size of the body. Rode et al. (2012) described a patient with Wallenberg's syndrome who reported a macrosomatognosia restricted to his left hemiface. In this patient, CVS temporarily alleviated distorted face perception. CVS also changed the perceived shape and position of phantom limbs in paraplegics (Le Chapelain et al., 2001). Similarly, CVS evoked the perception of a phantom limb in amputees who did not experience phantoms before, or altered the phantom perception in those who experienced phantoms already (André et al., 2001). This indicates that CVS can influence mental representations of a no-longer existing body segment and suggests that vestibular signals project to multisensory brain regions representing the body's metric properties. Yet, these observations were based 
Table 1 | Evidence of multisensory integration in three vestibulo-thalamo-cortical structures.

\section{Anatomical structure Evidence of multisensory integration}

Vestibular nuclei

Vestibular nuclei neurons respond to vestibular, visual (optokinetic stimulation: Waespe and Henn, 1978), tactile, proprioceptive (Roy and Cullen, 2004) and eye movements signals (Tomlinson and Robinson, 1984). These neurons integrate signals from otoliths and semicircular canals afferents to discriminate between head translations and head tilts, as well as to distinguish between active (or voluntary) and passive (or involuntary) head movements (review in Angelaki and Cullen, 2008).

Thalamus Vestibular thalamic neurons are characterized by very similar responses that have been described for vestibular nuclei neurons, i.e., they respond to visual, tactile, and proprioceptive stimuli (review in Lopez and Blanke, 2011). For example, about half of the vestibular neurons in the cat LGN respond to optokinetic stimulation (Magnin and Putkonen, 1978) and most of them are also driven by saccadic eye movements. Vestibular neurons in the VPL, VPM, and VPI respond to proprioceptive signals from joints and muscles (Deecke et al., 1977; Blum and Gilman, 1979) and code for passive movements of the neck, shoulders, legs, and vertebral column. Thalamic vestibular neurons also respond to tactile stimulation applied to the animal's paws (Sans et al., 1970).

Cerebral cortex Vestibulo-visuo-somatosensory convergence has been reported in the PIVC, at the junction of the insula with the retroinsular and somatosensory cortex (Grüsser et al., 1990a,b; Guldin and Grüsser, 1998). Visual-vestibular convergence has also been reported in the extrastriate visual area MST, a major region for self-motion perception based on optic flows (Bremmer et al., 1999; Gu etal., 2006). Vestibular-somatosensory convergence has been reported in the intraparietal sulcus and primary somatosensory cortex in monkeys (areas $2 \mathrm{v}$ and $3 a v$ in the hand/arm and neck/trunk representations) and in the secondary somatosensory cortex in humans (Schwarz and Fredrickson, 1971; Bottini et al., 1995, 2001, 2005; Guldin and Grüsser, 1998; Bremmer etal., 2002; Fasold et al., 2008).

only on patients' reports. Lopez et al. (2012b) demonstrated similar influence of CVS by using psychophysical measures in healthy participants. The influence of CVS on the perceived shape and size of the body was measured using a tactile distance comparison task and a proprioceptive judgment task. The results showed that CVS known to stimulate the right cerebral hemisphere modified the perceived size of the left hand, that appeared to be enlarged. This finding was later corroborated by the application of GVS (Ferrè et al., 2013).

\section{NEUROPHYSIOLOGICAL HYPOTHESIS}

Neuroimaging studies have revealed the implication of the posterior parietal cortex in body shape and size perception. In particular, the perception of the current position of body segments is thought to rely on the superior parietal lobule and intraparietal region (Wolpert et al., 1998; Félician etal., 2004; Corradi-Dell'Acqua et al., 2008, 2009). The inferior parietal lobule is also particularly relevant since electrical stimulation of the angular gyrus distorted body schema in epileptic patients (Blanke et al., 2002) and because transcranial direct current stimulation applied over the right angular gyrus modified body representations (Spitoni et al., 2013). Neuroimaging studies further revealed the implication of the parietal operculum and posterior insula as they contain somatotopic representations of the body (Eickhoff et al., 2007; Corradi-Dell'Acqua et al., 2009; Hashimoto and Iriki, 2013). Importantly, these parietal and insular regions process vestibular signals and the parietal operculum has even been proposed as the core vestibular cortex (Guldin and Grüsser, 1998; Eickhoff et al., 2006; Lopez et al., 2012a; zu Eulenburg et al., 2012). It is interesting to note that animal data revealed vestibulo-somatosensory convergence in parietal cortex, intraparietal sulcus, and operculo-insular cortex (Grüsser et al., 1990a,b, 1994; Bremmer et al., 2002). Bottini and colleagues showed that the parieto-insular cortex is a region where CVS interferes with tactile perception (Bottini et al., 1995, 2001, 2005; Ferrè et al., 2012). Accordingly, abnormal vestibular signals arriving in these regions during vertigo attacks may interfere with somatosensory processing. The misinterpretation of postural somesthetic signals from the neck may explain the patients' reports that their neck or head is enlarged. In support of this view is the fact that CVS and GVS produce similar effects in healthy volunteers (Lopez et al., 2012b; Ferrè et al., 2013).

\section{EMBODIMENT OR THE SENSE OF UNITY BETWEEN THE SELF AND THE BODY CLINICAL DESCRIPTION}

Vestibular patients may lose connection with their body and may be subject to an out-of-body experience (OBE). During an OBE, subjects localize their self outside their body, at a location that is often elevated (i.e., floating in the room), and experience seeing the environment from this disembodied location. Subjects may also experience seeing their own body (i.e., autoscopy), a double with which they strongly self-identify (Brugger, 1997; Blanke et al., 2004; Blanke and Mohr, 2005; Lopez et al., 2008; Blanke, 2012). Yet, clear cases of full-blown OBEs due to vestibular disorders seem very rare. Bonnier (1905) described the case of a loss of self-body unity: "it seemed to [the patient] that he was divided into two persons, one who had not changed posture, and another new person on his right, looking somewhat outwardly. Then the two somatic individuals approached each other, merged, and the vertigo disappeared." Illusory perceptions of doubles in vestibular pathology were also reported by Skworzoff (1931): one patient 
saw herself (i.e. autoscopy) for a moment in day light (Case 5, p. 764). Another patient saw and felt every day his own double (Case 6, p. 764). The same patient also reported in some instances sensations of flying, which could be evocative of an otolithic dysfunction.

\section{EXPERIMENTAL EVIDENCE}

Vestibular stimulation in healthy participants can strongly modify experienced self-location. GVS creates illusory motion of the entire body, i.e., dissociation between the perceived self-location (that appears tilted toward the cathode) and physical body location (Fitzpatrick and Day, 2004; Lenggenhager et al., 2008). Lopez et al. (2008) have proposed that such dissociation between self and body location reflects a type of partial disembodiment that is reminiscent of OBEs of neurological origin. Another indirect evidence of a vestibular contribution to embodied self-location comes from the observation that OBEs are more frequent in patients lying than sitting or standing upright (Blanke and Mohr, 2005). According to Green (1968), about 73\% of OBEs occur spontaneously when healthy subjects are lying down, and less often in sitting or standing subjects, suggesting a strong contribution of gravitational vestibular signals to self-location and embodiment.

\section{NEUROPHYSIOLOGICAL HYPOTHESIS}

A neurophysiological model by Blanke and colleagues posits that during OBEs a triple sensory misintegration, with conflicting vestibular, visual, and somatosensory signals, may occur in multisensory brain regions such as the temporo-parietal junction (Blanke et al., 2002, 2004; Blanke and Mohr, 2005; Lopez et al., 2008; Blanke, 2012). This model is supported by the fact that vestibular sensations (e.g., floating, lightness, elevation) occur often during OBEs of neurological origin (Devinsky et al., 1989; Blanke et al., 2002, 2004; Lopez et al., 2010; Heydrich et al., 2011). In addition, brain areas that are the most commonly damaged in OBE patients overlap with the vestibular cortex at the temporoparietal junction (Blanke et al., 2004; Ionta et al., 2011). Altogether, these data suggest a close relation between the phenomenal experience of a disembodied self and vestibular misintegration (Lopez and Blanke, 2007; Lopez et al., 2008; Blanke, 2012). Accordingly, the loss of self-body unity in vestibular patients may be due to sensory mismatch created by vertigo attacks at the temporo-parietal junction and posterior insula, two regions the metabolism of which is strongly disorganized by vestibular disorders (Bense et al., 2004; Alessandrini et al., 2013). Interfering with the temporoparietal junction by electrical stimulation has also been showed to induce both OBE and vestibular sensations (Penfield, 1955; Blanke et al., 2002; De Ridder et al., 2007). Vertigo attacks may produce a similar type of interference as those intracranial stimulations, but to a weaker extent, since full-blown OBEs were rarely reported in vestibular pathology.

\section{AGENCY \\ CLINICAL DESCRIPTION}

The loss of self-body connection described above is also evident in the motor control domain. A minimal sense of selfhood has been related to the sense of agency, the experience of being the agent of one's own actions (Franck et al., 2001; Jeannerod, 2006, 2009).
Interestingly, vestibular patients report more often than healthy participants the experience of "not being in control of their self" (Sang et al., 2006; Jauregui-Renaud et al., 2008b). For example, a patient with a bilateral Menière's disease reported during vertigo attacks "watching something happen and not being a part of it. It's just a feeling of not being there, participating in what's going on" (Case 2, p. 532 in Grigsby and Johnston, 1989). Vestibular patients often report that their actions do not seem to match their intentions. Even when tested at a compensated stage of a vestibular loss, patients perceive instability and dizziness during walking and standing despite no evident sign of postural unbalance.

\section{EXPERIMENTAL EVIDENCE}

To date, the role of vestibular signals in the sense of agency has not been measured experimentally. However, it has been showed that CVS evoked in healthy participants significantly stronger feeling of "not being in control of the self" than control stimulation (Lopez et al., 2012b). In addition, GVS altered the ability to perform and predict hand movements (Bresciani etal., 2002; Guillaud et al., 2011), but agency was not measured directly in these experiments.

\section{NEUROPHYSIOLOGICAL HYPOTHESIS}

Vestibular patients may report altered sense of agency because vestibular organs do not correctly encode the consequences of their actions. Patients tend to underestimate their body displacements and misinterpret the direction of body movements (Cohen, 2000; Borel et al., 2004), revealing the crucial role of vestibular signals in spatial updating during active and passive whole-body motions (e.g., Frissen et al., 2011; Campos et al., 2012). Errors in sensory coding can introduce a mismatch between vestibular, visual, and somatosensory feedback about self-initiated movements, as well as a discrepancy with the efferent signals from the motor command. Behavioral studies showed that agency is based on congruent sensory feedback from one's actions: introducing a mismatch (amplitude or direction of motion) between the visual and proprioceptive consequences of an action impairs agency (Fourneret and Jeannerod, 1998; Farrer et al., 2003b, 2008a; Kannape et al., 2010). I speculate that an additional factor may be responsible for distorted sense of agency in vestibular patients: a temporal mismatch between an action and the sensory feedback from this action. Interestingly, perception of time is altered in vestibular patients (Israel et al., 2004) and introducing a delay between the executed and seen movement disturb agency (Franck et al., 2001). Neuroimaging studies have revealed that the insula and the temporo-parietal junction are involved in agency (Spence et al., 1997; Farrer and Frith, 2002; Farrer etal., 2003a, 2004, 2008b). This reiterates the contribution of two main vestibular regions to a crucial bodily experience of self-consciousness. In light of these points, vestibular dysfunctions are therefore likely to create a spatiotemporal mismatch between efferent motor commands and feedback from an action, resulting in a disturbed sense of agency.

\section{DEPERSONALIZATION AND DEREALIZATION CLINICAL DESCRIPTION}

Most of the bodily disturbances described in the previous sections are part of depersonalization, a dissociative disorder characterized 
by the loss of familiarity of the self and surrounding and by a detachment from the self, that may be experienced as unreal (Simeon and Abugel, 2006). Early in the last century, Schilder $(1914,1935)$ already proposed a vestibular contribution to depersonalization and derealization (DD). More recently, Grigsby and Johnston (1989) collected experiences of DD in Menière's disease patients: a patient described DD as "a sense of unreality" and claimed "I feel like I'm outside of myself. I feel like I'm not in myself" (p. 531). Another patient reported "I am not actually being there or having anything to do with my body" (p. 532). More recently, the use of the Cox and Swinson (2002) questionnaire revealed that vestibular patients have more frequent and more severe DD symptoms than controls (Sang et al., 2006; Jauregui-Renaud et al., 2008b). Symptoms included sensations of "déjà vu," "body feels strange" and the experience of feeling "spacey" or "spaced out."

\section{EXPERIMENTAL EVIDENCE}

Yen Pik Sang et al. (2006) applied CVS in healthy volunteers and showed that it increased the frequency of DD symptoms such as "surroundings seem strange and unreal," "time seems to pass very slowly" and "body feels strange/different in some way." This finding was confirmed during bilateral CVS (Lopez et al., 2012b). It is not known, however, how long these effects persist.

\section{NEUROPHYSIOLOGICAL HYPOTHESIS}

Discrepancy between vestibular and other body-related signals may deteriorate the experience of the body and surroundings, leading to DD. In line with this view is the observation that various sensory dysfunctions increase the frequency of DD symptoms (vestibular, visual, auditory: Jauregui-Renaud et al., 2008a,b; somatosensory: Lenggenhager et al., 2012). The superior temporal and inferior parietal cortices are the best candidates to explain the vestibular influence on DD. During stimulation of the superior temporal cortex, Penfield $(1947,1955)$ evoked sensations of "déjà vu" and altered self-body relations ("I feel queer, as though I were floating away" and "I have a queer sensation as if I am not here," Penfield, 1947, p. 342). Interestingly, the sites of these stimulations overlapped those where vestibular sensations were evoked. In a PET study, Simeon et al. (2000) showed that DD were related to changes in brain metabolisms in regions that were also activated by CVS and GVS (superior temporal gyrus and temporo-parietal junction). Of particular interest here is the study by Bense et al. (2004) showing that very similar regions have altered metabolism during vestibular neuritis. This anatomical overlap strongly suggests that vestibular dysfunction disorganizes brain metabolism, multisensory integration, and eventually structure and connections in the multisensory temporo-parietal cortex, and this may be the underlying mechanism of DD in vestibular patients.

\section{CONCLUSION}

A better understanding of cortical vestibular processing, as well as of how CVS and GVS influence body and self perceptions, has provided the basis for a neuroscientific account of a so far under-recognized type of vestibular symptom - alterations in bodily self-consciousness. I have summarized evidence showing that abnormal forms of bodily self-consciousness in vestibular disorders may result from sensory conflict or mismatch in multisensory brain regions. This hypothesis should now be put under scientific scrutiny by correlating changes in bodily self-consciousness (e.g., subjective reports using DD questionnaires and objective measures of altered sense of agency and self-location; Kannape et al., 2010) with changes in metabolism and structure in the vestibular cortex (e.g., Bense et al., 2004; voxel-based morphometry: zu Eulenburg et al., 2010). In addition, I have drawn parallels between experimental evidence and clinical observations in vestibular patients to clarify the neural and sensory mechanisms of bodily selfconsciousness. Future research in the field should endeavor to make the same comparisons to further our understanding of the underlying multisensory mechanisms of bodily self-consciousness (see Blanke, 2012). In particular, several bodily experiences should now be systematically quantified in vestibular patients to obtain a full description of the consequences of vestibular dysfunctions, including changes in the patient's self, mood, and personality. I am optimistic that these data will also impact on the multisensory models of self-consciousness currently developed by neuroscientists and philosophers and in which the contribution of the vestibular system is often neglected.

\section{ACKNOWLEDGMENTS}

The research leading to these results has received funding from the People Programme (Marie Curie Actions) of the European Union's Seventh Framework Programme (FP7/2007-2013) under REA grant agreement number 333607 (“BODILYSELF, vestibular and multisensory investigations of bodily self-consciousness"). This work was also supported by a grant from the Volkswagenstiftung's European Platform for Life Sciences, Mind Sciences, and the Humanities ["The (Un)bound Body Project. Exploring the constraints of embodiment \& the limits of body representation"]. I am grateful to Dr. Bigna Lenggenhager and Dr. Caroline Falconer for helpful comments on the manuscript.

\section{REFERENCES}

Alessandrini, M., Pagani, M., Napolitano, B., Micarelli, A., Candidi, M., Bruno, E., et al. (2013). Early and phasic cortical metabolic changes in vestibular neuritis onset. PLoS ONE 8:e57596. doi: 10.1371/journal.pone.0057596

André, J. M., Martinet, N., Paysant, J., Beis, J. M., and Le Chapelain, L. (2001). Temporary phantom limbs evoked by vestibular caloric stimulation in amputees. Neuropsychiatry Neuropsychol. Behav. Neurol. 14, 190-196.

Angelaki, D. E., and Cullen, K. E. (2008). Vestibular system: the many facets of a multimodal sense. Annu. Rev. Neurosci. 31, 125-150. doi: 10.1146/annurev.neuro.31.060407.125555

Bense, S., Bartenstein, P., Lochmann, M., Schlindwein, P., Brandt, T., and Dieterich, M. (2004). Metabolic changes in vestibular and visual cortices in acute vestibular neuritis. Ann. Neurol. 56, 624-630. doi: 10.1002/ana.20244

Berlucchi, G., and Aglioti, S. M. (2010). The body in the brain revisited. Exp. Brain Res. 200, 25-35. doi: 10.1007/s00221-009-1970-7

Blanke, O. (2012). Multisensory brain mechanisms of bodily self-consciousness. Nat. Rev. Neurosci. 13, 556-571.

Blanke, O., Landis, T., Spinelli, L., and Seeck, M. (2004). Out-of-body experience and autoscopy of neurological origin. Brain 127, 243-258. doi: 10.1093/brain/awh040

Blanke, O., and Mohr, C. (2005). Out-of-body experience, heautoscopy, and autoscopic hallucination of neurological origin implications for neurocognitive mechanisms of corporeal awareness and self-consciousness. Brain Res. Brain Res. Rev. 50, 184-199. doi: 10.1016/j.brainresrev.2005.05.008

Blanke, O., Ortigue, S., Landis, T., and Seeck, M. (2002). Stimulating illusory own-body perceptions. Nature 419, 269-270. doi: 10.1038/419269a 
Blum, P. S., and Gilman, S. (1979). Vestibular, somatosensory, and auditory input to the thalamus of the cat. Exp. Neurol. 65, 343-354. doi: 10.1016/00144886(79)90103-1

Bonnier, P. (1905). L'Aschématie. Rev. Neurol. (Paris) 12, 605-609.

Bonnier, P. (1893). Le vertige. Paris: Rueff.

Borel, L., Harlay, F., Lopez, C., Magnan, J., Chays, A., and Lacour, M. (2004). Walking performance of vestibular-defective patients before and after unilateral vestibular neurotomy. Behav. Brain Res. 150, 191-200. doi: 10.1016/S0166-4328(03)00257-2

Borel, L., Lopez, C., Péruch, P., and Lacour, M. (2008). Vestibular syndrome: a change in internal spatial representation. Neurophysiol. Clin. 38, 375-389. doi: 10.1016/j.neucli.2008.09.002

Bottini, G., Karnath, H. O., Vallar, G., Sterzi, R., Frith, C. D., Frackowiak, R. S., et al. (2001). Cerebral representations for egocentric space: functional-anatomical evidence from caloric vestibular stimulation and neck vibration. Brain 124, 1182-1196. doi: 10.1093/brain/124.6.1182

Bottini, G., Paulesu, E., Gandola, M., Loffredo, S., Scarpa, P., Sterzi, R., et al. (2005). Left caloric vestibular stimulation ameliorates right hemianesthesia. Neurology 65, 1278-1283. doi: 10.1212/01.wnl.0000182398.14088.e8

Bottini, G., Paulesu, E., Sterzi, R., Warburton, E., Wise, R. J., Vallar, G., et al. (1995). Modulation of conscious experience by peripheral sensory stimuli. Nature 376, 778-781. doi: 10.1038/376778a0

Brandt, T., Schautzer, F., Hamilton, D. A., Bruning, R., Markowitsch, H. J., Kalla, R., et al. (2005). Vestibular loss causes hippocampal atrophy and impaired spatial memory in humans. Brain 128, 2732-2741. doi: 10.1093/brain/awh617

Bremmer, F., Klam, F., Duhamel, J. R., Ben Hamed, S., and Graf, W. (2002). Visualvestibular interactive responses in the macaque ventral intraparietal area (VIP). Eur. J. Neurosci. 16, 1569-1586. doi: 10.1046/j.1460-9568.2002.02206.x

Bremmer, F., Kubischik, M., Pekel, M., Lappe, M., and Hoffmann, K. P. (1999). Linear vestibular self-motion signals in monkey medial superior temporal area. Ann. N. Y. Acad. Sci. 871, 272-281. doi: 10.1111/j.1749-6632.1999.tb09191.x

Bresciani, J. P., Blouin, J., Popov, K., Bourdin, C., Sarlegna, F., Vercher, J. L., et al. (2002). Galvanic vestibular stimulation in humans produces online arm movement deviations when reaching towards memorized visual targets. Neurosci. Lett. 318, 34-38. doi: 10.1016/S0304-3940(01)02462-4

Brugger, P. (1997). Illusory reduplication of one's own body: phenomenology and classification of autoscopic phenomena. Cogn. Neuropsychiatry 2, 19-38. doi: 10.1080/135468097396397

Butler, J. S., Smith, S. T., Campos, J. L., and Bülthoff, H. H. (2010). Bayesian integration of visual and vestibular signals for heading. J. Vis. 10, 23. doi: $10.1167 / 10.11 .23$

Campos, J. L., Butler, J. S., and Bülthoff, H. H. (2012). Multisensory integration in the estimation of walked distances. Exp. Brain Res. 218, 551-565. doi: 10.1007/s00221-012-3048-1

Chen, A., DeAngelis, G. C., and Angelaki, D. E. (2010). Macaque parieto-insular vestibular cortex: responses to self-motion and optic flow. J. Neurosci. 30, 30223042. doi: 10.1523/JNEUROSCI.4029-09.2010

Cohen, H. S. (2000). Vestibular disorders and impaired path integration along a linear trajectory. J. Vestib. Res. 10, 7-15.

Corradi-Dell'Acqua, C., Hesse, M. D., Rumiati, R. I., and Fink, G. R. (2008). Where is a nose with respect to a foot? The left posterior parietal cortex processes spatial relationships among body parts. Cereb. Cortex 18, 2879-2890. doi: 10.1093/cercor/bhn046

Corradi-Dell'Acqua, C., Tomasino, B., and Fink, G. R. (2009). What is the position of an arm relative to the body? Neural correlates of body schema and body structural description. J. Neurosci. 29, 4162-4171. doi: 10.1523/JNEUROSCI.4861-08. 2009

Cox, B. J., and Swinson, R. P. (2002). Instrument to assess depersonalizationderealization in panic disorder. Depress. Anxiety 15, 172-175. doi: 10.1002/da.10051

Curthoys, I. S., and Halmagyi, G. M. (1995). Vestibular compensation: a review of the oculomotor, neural, and clinical consequences of unilateral vestibular loss. J. Vestib. Res. 5, 67-107. doi: 10.1016/0957-4271(94)00026-X

Deecke, L., Schwarz, D. W., and Fredrickson, J. M. (1977). Vestibular responses in the rhesus monkey ventroposterior thalamus. II. Vestibulo-proprioceptive convergence at thalamic neurons. Exp. Brain Res. 30, 219-232.

De Ridder, D., Van Laere, K., Dupont, P., Menovsky, T., and Van de Heyning, P. (2007). Visualizing out-of-body experience in the brain. N. Engl. J. Med. 357, 1829-1833. doi: 10.1056/NEJMoa070010 de Vignemont, F. (2010). Body schema and body image - pros and cons. Neuropsychologia 48, 669-680. doi: 10.1016/j.neuropsychologia.2009.09.022

Devinsky, O., Feldmann, E., Burrowes, K., and Bromfield, E. (1989). Autoscopic phenomena with seizures. Arch. Neurol. 46, 1080-1088. doi: 10.1001/archneur.1989.00520460060015

Dieguez, S., Staub, F., and Bogousslavsky, J. (2007). "Asomatognosia," in The Behavioral and Cognitive Neurology of Stroke, eds J. Bogousslavsky and O. Godefroy (New York: Cambridge University Press), 215-253.

Eickhoff, S. B., Grefkes, C., Zilles, K., and Fink, G. R. (2007). The somatotopic organization of cytoarchitectonic areas on the human parietal operculum. Cereb. Cortex 17, 1800-1811. doi: 10.1093/cercor/bhl090

Eickhoff, S. B., Weiss, P. H., Amunts, K., Fink, G. R., and Zilles, K. (2006). Identifying human parieto-insular vestibular cortex using fMRI and cytoarchitectonic mapping. Hum. Brain Mapp. 27, 611-621. doi: 10.1002/hbm.20205

Farrer, C., Bouchereau, M., Jeannerod, M., and Franck, N. (2008a). Effect of distorted visual feedback on the sense of agency. Behav. Neurol. 19, 53-57.

Farrer, C., Frey, S. H., Van Horn, J. D., Tunik, E., Turk, D., Inati, S., et al. (2008b). The angular gyrus computes action awareness representations. Cereb. Cortex 18, 254-261. doi: 10.1093/cercor/bhm050

Farrer, C., Franck, N., Frith, C. D., Decety, J., Georgieff, N., d' Amato, T., et al. (2004). Neural correlates of action attribution in schizophrenia. Psychiatry Res. 131, 31-44. doi: 10.1016/j.pscychresns.2004.02.004

Farrer, C., Franck, N., Georgieff, N., Frith, C. D., Decety, J., and Jeannerod, M. (2003a). Modulating the experience of agency: a positron emission tomography study. Neuroimage 18, 324-333. doi: 10.1016/S1053-8119(02)00041-1

Farrer, C., Franck, N., Paillard, J., and Jeannerod, M. (2003b). The role of proprioception in action recognition. Conscious. Cogn. 12, 609-619. doi: 10.1016/S1053-8100(03)00047-3

Farrer, C., and Frith, C. D. (2002). Experiencing oneself vs another person as being the cause of an action: the neural correlates of the experience of agency. Neuroimage 15, 596-603. doi: 10.1006/nimg.2001.1009

Fasold, O., Heinau, J., Trenner, M. U., Villringer, A., and Wenzel, R. (2008). Proprioceptive head posture-related processing in human polysensory cortical areas. Neuroimage 40, 1232-1242. doi: 10.1016/j.neuroimage.2007.12.060

Félician, O., Romaiguère, P., Anton, J. L., Nazarian, B., Roth, M., Poncet, M., et al. (2004). The role of human left superior parietal lobule in body part localization. Ann. Neurol. 55, 749-751. doi: 10.1002/ana.20109

Ferrè, E. R., Bottini, G., and Haggard, P. (2012). Vestibular inputs modulate somatosensory cortical processing. Brain Struct. Funct. 217, 859-864. doi: 10.1007/s00429-012-0404-7

Ferrè, E. R., Vagnoni, E., and Haggard, P. (2013). Vestibular contributions to bodily awareness. Neuropsychologia 51, 1445-1452. doi: 10.1016/j.neuropsychologia.2013.04.006

Fetsch, C. R., Pouget, A., DeAngelis, G. C., and Angelaki, D. E. (2012). Neural correlates of reliability-based cue weighting during multisensory integration. Nat. Neurosci. 15, 146-154. doi: 10.1038/nn.2983

Fitzpatrick, R. C., and Day, B. L. (2004). Probing the human vestibular system with galvanic stimulation. J. Appl. Physiol. 96, 2301-2316. doi: 10.1152/japplphysiol.00008.2004

Fourneret, P., and Jeannerod, M. (1998). Limited conscious monitoring of motor performance in normal subjects. Neuropsychologia 36, 1133-1140. doi: 10.1016/S0028-3932(98)00006-2

Franck, N., Farrer, C., Georgieff, N., Marie-Cardine, M., Dalery, J., d'Amato, T., et al. (2001). Defective recognition of one's own actions in patients with schizophrenia. Am. J. Psychiatry 158, 454-459. doi: 10.1176/appi.ajp.158.3.454

Frissen, I., Campos, J. L., Souman, J. L., and Ernst, M. O. (2011). Integration of vestibular and proprioceptive signals for spatial updating. Exp. Brain Res. 212, 163-176. doi: 10.1007/s00221-011-2717-9

Gallagher, S. (2005). How the Body Shapes the Mind. New York: Oxford University Press.

Green, C. E. (1968). Out-of-Body Experiences. Oxford: Institute of Psychophysical Research.

Grigsby, J. P., and Johnston, C. L. (1989). Depersonalization, vertigo and Meniere's disease. Psychol. Rep. 64, 527-534. doi: 10.2466/pr0.1989.64.2.527

Grüsser, O. J., Guldin, W. O., Mirring, S., and Salah-Eldin, A. (1994). "Comparative physiological and anatomical studies of the primate vestibular cortex," in Structural and Functional Organization of the Neocortex, eds B. Albowitz, K. Albus, U. Kuhnt, H. C. Nothdurf, and P. Wahle (Berlin: Springer-Verlag), 358-371. 
Grüsser, O. J., Pause, M., and Schreiter, U. (1990a). Localization and responses of neurones in the parieto-insular vestibular cortex of awake monkeys (Macaca fascicularis). J. Physiol. 430, 537-557.

Grüsser, O. J., Pause, M., and Schreiter, U. (1990b). Vestibular neurones in the parieto-insular cortex of monkeys (Macaca fascicularis): visual and neck receptor responses. J. Physiol. 430, 559-583.

Gu, Y., Watkins, P. V., Angelaki, D. E., and DeAngelis, G. C. (2006). Visual and nonvisual contributions to three-dimensional heading selectivity in the medial superior temporal area. J. Neurosci. 26, 73-85. doi: 10.1523/JNEUROSCI.235605.2006

Guillaud, E., Simoneau, M., and Blouin, J. (2011). Prediction of the body rotationinduced torques on the arm during reaching movements: evidence from a proprioceptively deafferented subject. Neuropsychologia 49, 2055-2059. doi: 10.1016/j.neuropsychologia.2011.03.035

Guldin, W. O., and Grüsser, O. J. (1998). Is there a vestibular cortex? Trends Neurosci. 21, 254-259. doi: 10.1016/S0166-2236(97)01211-3

Hashimoto, T., and Iriki, A. (2013). Dissociations between the horizontal and dorsoventral axes in body-size perception. Eur. J. Neurosci. 37, 1747-1753. doi: 10.1111/ejn. 12187

Held, R., and Hein, A. (1963). Movement-produced stimulation in the development of visually guided behavior. J. Comp. Physiol. Psychol. 56, 872-876. doi: 10.1037/h0040546

Heydrich, L., Lopez, C., Seeck, M., and Blanke, O. (2011). Partial and full own-body illusions of epileptic origin in a child with right temporoparietal epilepsy. Epilepsy Behav. 20, 583-586. doi: 10.1016/j.yebeh.2011.01.008

Ionta, S., Heydrich, L., Lenggenhager, B., Mouthon, M., Fornari, E., Chapuis, D., et al. (2011). Multisensory mechanisms in temporo-parietal cortex support self-location and first-person perspective. Neuron 70, 363-374. doi: 10.1016/j.neuron.2011.03.009

Israel, I., Capelli, A., Sable, D., Laurent, C., Lecoq, C., and Bredin, J. (2004). Multifactorial interactions involved in linear self-transport distance estimate: a place for time. Int. J. Psychophysiol. 53, 21-28. doi: 10.1016/j.ijpsycho.2004.01.002

Jauregui-Renaud, K., Ramos-Toledo, V., Aguilar-Bolanos, M., Montano-Velazquez, B., and Pliego-Maldonado, A. (2008a). Symptoms of detachment from the self or from the environment in patients with an acquired deficiency of the special senses. J. Vestib. Res. 18, 129-137.

Jauregui-Renaud, K., Sang, F. Y., Gresty, M. A., Green, D. A., and Bronstein, A. M. (2008b). Depersonalisation/derealisation symptoms and updating orientation in patients with vestibular disease. J. Neurol. Neurosurg. Psychiatry 79, 276-283. doi: 10.1136/jnnp.2007.122119

Jeannerod, M. (2006). Motor Cognition: What Actions Tell to the Self. Oxford: Oxford University Press.

Jeannerod, M. (2009). The sense of agency and its disturbances in schizophrenia: a reappraisal. Exp. Brain Res. 192, 527-532. doi: 10.1007/s00221-008-1533-3

Kannape, O. A., Schwabe, L., Tadi, T., and Blanke, O. (2010). The limits of agency in walking humans. Neuropsychologia 48, 1628-1636. doi: 10.1016/j.neuropsychologia.2010.02.005

Le Chapelain, L., Beis, J. M., Paysant, J., and Andre, J. M. (2001). Vestibular caloric stimulation evokes phantom limb illusions in patients with paraplegia. Spinal Cord 39, 85-87. doi: 10.1038/sj.sc.3101093

Lenggenhager, B., Lopez, C., and Blanke, O. (2008). Influence of galvanic vestibular stimulation on egocentric and object-based mental transformations. Exp. Brain Res. 184, 211-221. doi: 10.1007/s00221-007-1095-9

Lenggenhager, B., Pazzaglia, M., Scivoletto, G., Molinari, M., and Aglioti, S. M. (2012). The sense of the body in individuals with spinal cord injury. PLoS ONE 7:e50757. doi: 10.1371/journal.pone.0050757

Lhermitte, J. (1939). L'image de notre corps. Paris: Nouvelle Revue Critique.

Longo, M. R., Azañón, E., and Haggard, P. (2010). More than skin deep: body representation beyond primary somatosensory cortex. Neuropsychologia 48, 655668. doi: 10.1016/j.neuropsychologia.2009.08.022

Lopez, C., and Blanke, O. (2007). "Neuropsychology and neurophysiology of selfconsciousness. Multisensory and vestibular mechanisms," in Hirnforschung und Menschenbild. Beiträge zur interdisziplinären Verständigung, eds A. Holderegger, B. Sitter-Liver, C. W. Hess, and G. Rager (Fribourg: Academic Press), 183-206.

Lopez, C., and Blanke, O. (2011). The thalamocortical vestibular system in animals and humans. Brain Res. Rev. 67, 119-146. doi: 10.1016/j.brainresrev.2010. 12.002
Lopez, C., Blanke, O., and Mast, F. W. (2012a). The vestibular cortex in the human brain revealed by coordinate-based activation likelihood estimation meta-analysis. Neuroscience 212, 159-179. doi: 10.1016/j.neuroscience.2012. 03.028

Lopez, C., Schreyer, H. M., Preuss, N., and Mast, F. W. (2012b). Vestibular stimulation modifies the body schema. Neuropsychologia 50, 1830-1837. doi: 10.1016/j.neuropsychologia.2012.04.008

Lopez, C., Halje, P., and Blanke, O. (2008). Body ownership and embodiment: vestibular and multisensory mechanisms. Neurophysiol. Clin. 38, 149-161. doi: 10.1016/j.neucli.2007.12.006

Lopez, C., Heydrich, L., Seeck, M., and Blanke, O. (2010). Abnormal self-location and vestibular vertigo in a patient with right frontal lobe epilepsy. Epilepsy Behav. 17, 289-292. doi: 10.1016/j.yebeh.2009.12.016

MacNeilage, P. R., Banks, M. S., Berger, D. R., and Bulthoff, H. H. (2007). A Bayesian model of the disambiguation of gravitoinertial force by visual cues. Exp. Brain Res. 179, 263-290. doi: 10.1007/s00221-006-0792-0

Magnin, M., and Putkonen, P. T. (1978). A new vestibular thalamic area: electrophysiological study of the thalamic reticular nucleus and of the ventral lateral geniculate complex of the cat. Exp. Brain Res. 32, 91-104. doi: 10.1007/BF00237394

Menninger-Lerchenthal, E. (1946). Der eigene Doppelgänger. Bern: Huber.

Penfield, W. (1947). Some observations on the cerebral cortex of man. Proc. R. Soc. Lond. B Biol. Sci. 134, 329-347. doi: 10.1098/rspb.1947.0017

Penfield, W. (1955). The twenty-ninth Maudsley lecture: the role of the temporal cortex in certain psychical phenomena. J. Ment. Sci. 101, 451-465.

Prsa, M., Gale, S., and Blanke, O. (2012). Self-motion leads to mandatory cue fusion across sensory modalities. J. Neurophysiol. 108, 2282-2291. doi: 10.1152/jn.00439.2012

Rode, G., Vallar, G., Revol, P., Tilikete, C., Jacquin-Courtois, S., Rossetti, Y., et al. (2012). Facial macrosomatognosia and pain in a case of Wallenberg's syndrome: selective effects of vestibular and transcutaneous stimulations. Neuropsychologia 50, 245-253. doi: 10.1016/j.neuropsychologia.2011.11.018

Roy, J. E., and Cullen, K. E. (2004). Dissociating self-generated from passively applied head motion: neural mechanisms in the vestibular nuclei. J. Neurosci. 24, 2102-2111. doi: 10.1523/JNEUROSCI.3988-03.2004

Sang, F. Y., Jauregui-Renaud, K., Green, D. A., Bronstein, A. M., and Gresty, M. A. (2006). Depersonalisation/derealisation symptoms in vestibular disease. J. Neurol. Neurosurg. Psychiatry 77, 760-766. doi: 10.1136/jnnp.2005.075473

Sans, A., Raymond, J., and Marty, R. (1970). Réponses thalamiques et corticales à la stimulation électrique du nerf vestibulaire chez le chat. Exp. Brain Res. 10, 265-275. doi: 10.1007/BF00235050

Schilder, P. (1914). Selbstbewusstein und Persönnlichkeitsbewusstein: eine psychopathologische Studie. Berlin: Springer.

Schilder, P. (1935). The Image and Appearance of the Human Body. New York: International Universities Press.

Schwarz, D. W. F., and Fredrickson, J. M. (1971). Rhesus monkey vestibular cortex: a bimodal primary projection field. Science 172, 280-281. doi: $10.1126 /$ science. 172.3980 .280

Serino, A., and Haggard, P. (2010). Touch and the body. Neurosci. Biobehav. Rev. 34, 224-236. doi: 10.1016/j.neubiorev.2009.04.004

Simeon, D., and Abugel, J. (2006). Feeling Unreal. Depersonalization Disorder and the Loss of the Self. New York: Oxford University Press.

Simeon, D., Guralnik, O., Hazlett, E. A., Spiegel-Cohen, J., Hollander, E., and Buchsbaum, M. S. (2000). Feeling unreal: a PET study of depersonalization disorder Am. J. Psychiatry 157, 1782-1788. doi: 10.1176/appi.ajp.157.11.1782

Skworzoff, K. (1931). Doppelgänger-Halluzinationen bei Kranken mit Funktionsstörungen des Labyrinths. Z. Gesamte Neurol. Psychiatr. 133, 762-766. doi: 10.1007/BF02909953

Smith, P. F. (1997). Vestibular-hippocampal interactions. Hippocampus 7, 465-471. doi: 10.1002/(SICI) 1098-1063(1997)7:5<465::AID-HIPO3>3.0.CO;2-G

Spence, S. A., Brooks, D. J., Hirsch, S. R., Liddle, P. F., Meehan, J., and Grasby, P. M. (1997). A PET study of voluntary movement in schizophrenic patients experiencing passivity phenomena (delusions of alien control). Brain 120(Pt 11), 1997-2011. doi: 10.1093/brain/120.11.1997

Spitoni, G. F., Pireddu, G., Cimmino, R. L., Galati, G., Priori, A., Lavidor, M., et al. (2013). Right but not left angular gyrus modulates the metric component of the mental body representation: a tDCS study. Exp. Brain Res. 228, 63-72. doi: 10.1007/s00221-013-3538-9 
Tomlinson, R. D., and Robinson, D. A. (1984). Signals in vestibular nucleus mediating vertical eye movements in the monkey. J. Neurophysiol. 51, 1121-1136.

Vallar, G., and Papagno, C. (2003). "Pierre Bonnier's (1905) cases of bodily 'aschematie," in Classic Cases in Neuropsychology, Vol. 2, eds C. Code, C. W. Wallesch, Y. Joanette, and A. Roch Lecours (New York: Psychology Press), $147-170$.

Vallar, G., and Rode, G. (2009). Commentary on Bonnier P. L'aschématie. Rev. Neurol. (Paris) 1905;13:605-9. Epilepsy Behav. 16, 397-400. doi: 10.1016/j.yebeh.2009.09.001

Waespe, W., and Henn, V. (1978). Conflicting visual-vestibular stimulation and vestibular nucleus activity in alert monkeys. Exp. Brain Res. 33, 203-211. doi: 10.1007/BF00238060

Wolpert, D. M., Goodbody, S. J., and Husain, M. (1998). Maintaining internal representations: the role of the human superior parietal lobe. Nat. Neurosci. 1, 529-533. doi: 10.1038/2245

Yen Pik Sang, F., Jauregui-Renaud, K., Green, D. A., Bronstein, A. M., and Gresty, M. A. (2006). Depersonalisation/derealisation symptoms in vestibular disease. J. Neurol. Neurosurg. Psychiatry 77, 760-766. doi: 10.1136/jnnp.2005.075473

zu Eulenburg, P., Caspers, S., Roski, C., and Eickhoff, S. B. (2012). Meta-analytical definition and functional connectivity of the human vestibular cortex. Neuroimage 60, 162-169. doi: 10.1016/j.neuroimage.2011. 12.032

zu Eulenburg, P., Stoeter, P., and Dieterich, M. (2010). Voxel-based morphometry depicts central compensation after vestibular neuritis. Ann. Neurol. 68, 241-249. doi: 10.1002/ana.22063

Conflict of Interest Statement: The author declares that the research was conducted in the absence of any commercial or financial relationships that could be construed as a potential conflict of interest.

Received: 21 October 2013; accepted: 21 November 2013; published online: 06 December 2013.

Citation: Lopez C (2013) A neuroscientific account of how vestibular disorders impair bodily self-consciousness. Front. Integr. Neurosci. 7:91. doi: 10.3389/fnint.2013.00091 This article was submitted to the journal Frontiers in Integrative Neuroscience. Copyright (C) 2013 Lopez. This is an open-access article distributed under the terms of the Creative Commons Attribution License (CC BY). The use, distribution or reproduction in other forums is permitted, provided the original author(s) or licensor are credited and that the original publication in this journal is cited, in accordance with accepted academic practice. No use, distribution or reproduction is permitted which does not comply with these terms. 